\title{
ГОСУДАРСТВЕННАЯ СЕМЕЙНАЯ ПОЛИТИКА И ПРАВОВОЙ СТАТУС РОДИТЕЛЕЙ: ПРОБЛЕМЫ СОВЕРШЕНСТВОВАНИЯ СЕМЕЙНОГО ЗАКОНОДАТЕЛЬСТВА
}

Аннотация: В настоящий период времени в России ведется работа над Концепцией соверщенствования семейного законодательства Российской Федерации. Автор обосновывает актуальность и основополагающий характер научных исследований правового статуса родителей с иелью выработки предложений в адрес законодателя. При этом приводятся аргументы в поддержку позиции разработчиков указанной Концеепции, поставленной под сомнение в заключении экспертов, о том, что первоочередной мерой должно стать устранение правовой неопределенности категориального аппарата. Объектом исследования являются отношения родителей и детей. Предметом исследования являются достижения науки преимущественно в сфере семейного, гражданского и общей теории права, законодательство и правоприменительная практика. В статье использованы общенаучные (анализ и синтез, абстрагирование и конкретизачия) и частно-научные методы исследования (формально-юридический, технико-юридический). В результате исследования предлагается авторский подход к пониманию терминов "родитель" и "ребенок", формулируются конкретные рекомендациии по обновлению положений ст. 47 и 54 Семейного кодекса Российской Федерации. Утверждается, что юридическим фактом необходимым и достаточным для возникновения правового статуса родителя является рождение ребенка. В этой связи предлагается изменение существующих правил регистрация рождения ребенка, формулируются выводы о необходимости внесения изменений в законодательство о регистрации актов гражданского состояния для приведения его в соответствии требованиям международного законодательства. Автор критикует практику отказа от родительских прав и обязанностей посредством оформления родителями дачи согласия на усыновление на будущее время и предлагает способ преодоления данной проблемы путем внесения изменений в положение ст. 129 СК РФ.

Ключевые слова: Регистрация рождения, правовой статус, родитель, ребенок, семейное законодательство, государственная семейная политика, демографическая политика, концепция, защчита детей, защита родительских прав.

Abstract: Currently, works is being done on the Concept of improving the family legislation of the Russian Federation. The author substantiates the relevance and importance of the scientific research of the legal status of parents in order to devise proposals for the legislator. Arguments are being made to support the positions of the authors of this Concept called into question by the conclusion of experts that the primary measure should become the elimination of legal uncertainty of the categorical apparatus. The object of this research is the relations between parents and children. The subject is the scientific achievements in the area of family, civil and general theory laws; legislation and legal practice. The author proposes an original approach towards the understanding of the terms "parent" and "child", and formulates specific recommendations on updates to the positions of Articles 47 and 54 of the Family Code of the Russian Federation. It is a juridical fact that the necessary and sufficient basis for status of a parent is birth of a child. Therefore, the author proposes to change the current rules of birth registration, and forms the conclusions on the need to make changes in the legislation on the registration of acts of civil condition in order to match the criteria of international legislation.

Keywords: Protection of children, concept, population policy, state family policy, family law, child, parent, legal status, birth registration, protection of parental rights. 
Д огматизация является непременным условием приспособления закона к потребностям правоприменения [1, с. 39]. В этой связи особое теоретическое и практическое значение представляют научные исследования, направленные на создание единой теоретической базы, содержащей обоснованные предложения в адрес законодателя. Современная наука семейного права постоянно обогащается результатами новых исследований проблематики статуса ребенка в семейных правоотношениях, обеспечения личных и имущественных прав и интересов детей [2]. Достаточно уделяется внимания вопросам содержания родителями детей [3]. Между тем исследований правового статуса родителей не проводилось, хотя мысль о том, что права родителей предопределяют права детей уже звучала в отдельных публикациях ученых. Так, например, Е. В. Князева отмечает: «Реализация и защита прав ребенка способствуют не только нормы, наделяющие правами самого несовершеннолетнего, но и те нормы, которые позволяют иным лицам, прежде всего, родителям ребенка, совершать действия, порождающие в дальнейшем правовые последствия для детей. .. Эти нормы являются правовой основой, с помощью которой несовершеннолетний может стать правообладателем и затем участвовать в осуществлении и защите ряда прав» [4]. Тем самым актуальным для развития науки семейного права представляется исследование проблем правового статуса родителей, выработка единого категориального аппарата, поиск и установление внутренних закономерностей развития правовой формы отношений родителей и детей.

Об актуальности и существенном значении указанных научных исследований в жизни общества и государства свидетельствует и тот факт, что возрождение семьи и традиционных семейных ценностей на сформированной научной основе, рассматривается в текущий период времени как наиболее приоритетные задачи демографической и семейной политики России. Признано, что законодательство, устанавливающее основания приобретения и содержание данного статуса, является той первоосновой, на которой возникают и с учетом которой развиваются любые юридические коммуникации родителей. Его положения, сформулированные еще в советский исторический период, должны быть концептуально переосмыслены.

Для решения данных задач Указом Президента утверждена Национальная стратегия действий в интересах детей на 2012-2017 годы [5]. Подготовлена и обсуждается «Концепция совершенствования семейного законодательства Российской Федерации» (далее
-Концепция) [6]. Разработчиками данной Концепции являются ведущие ученые в сфере семейного права, они отмечают, что одной из причин ослабления института семьи является отсталость семейного законодательства, в котором отсутствуют нормы, призванные укрепить авторитет родительской власти: «Семейный кодекс Российской Федерации был принят в 1995 году и ни разу не подвергался системному анализу и пересмотру. Между тем за двадцатилетний период истории России в условиях новой Конституции Российской Федерации отраслевое законодательство России существенно изменилось, появилось объемное и развитое региональное законодательство. Положения же семейного законодательства, умаляющие роль родителей в решении вопросов воспитания и развития ребенка, узаконивающие свободу усмотрения для органов опеки и попечительства при принятии решений, связанных с вмешательством в семейную жизнь, остаются незыблемыми» [6]. Изложенное подтверждает актуальность исследования вопросов совершенствования действующего семейного законодательства о правах и обязанностях родителей.

В рамках настоящей статьи изложено видение автора отдельных аспектов проблемы научного исследования правового статуса родителей и предпринята попытка теоретического обоснования необходимых изменений семейного законодательства в поддержку разработчиков Концепции. Так, по мнению указанных специалистов, первоочередными мерами по совершенствованию семейного законодательства должно стать устранение правовой неопределенности категориального аппарата, а в частности, определение содержания терминов «родители и лица, их заменяющие», «ребенок (дети)». В то же время представляются спорными аргументы в поддержку противоположной позиции, изложенные в Экспертном заключении по проекту Концепции совершенствования семейного законодательства Российской Федерации и Предложений по совершенствованию семейного законодательства Совета при Президенте РФ по кодификации и совершенствованию гражданского законодательства от 07.07.2014 № 132-1/2014) (далее - Экспертное заключение): «Содержание многих понятий, включенных в указанный перечень, разумно вытекает из смысла действующих правовых норм. Например, определение понятия «ребенок» содержит пункт 1 статьи 54 СК, согласно которому ребенком признается лицо, не достигшее возраста восемнадцати лет (совершеннолетия)» [7].

Следует заметить, что правовое понятие «ребенок» используется в семейном и в гражданском законодательстве наряду с понятиями «несовершеннолетние» 
DOI: $10.7256 / 1811-9018.2015 .11 .16652$

При цитировании этой статьи сноска на dоі обязательна

\section{Право и политика $11(191) \cdot 2015$}

и «дети». Как правило, эти термины используются в качестве синонимов для обозначения лиц, не достигших возраста 18 лет. Между тем новейшие исследования правового статуса ребенка [2] доказывают нецелесообразность такого подхода, не позволяющего учесть зависимость этих категорий от характера отношений с участием детей, возраста детей, специфики юридических фактов, что, в конечном счете, негативно отражается на законотворческой и правоприменительной деятельности. В этой связи ученые обосновывают необходимость придерживаться дальнейшего терминологического единообразия: в семейном праве применять понятие «ребенок», подчеркивая тем самым первостепенное значение в таких отношениях связи ребенка с родителями (родство) или связи с иными лицами на предусмотренных основаниях (опекуны, попечители, усыновители и т.д.); в сфере гражданского права исследователями предлагается употреблять термин «несовершеннолетние» с учетом деления их по возрасту на определенные группы (малолетние, несовершеннолетние в возрасте от 14 до 18 лет). При этом общим термином для обеих отраслей права, независимо от возраста и родства, является дети.

Действующий Семейный кодекс Российской Федерации (далее - СК РФ), как и отмечено в Экспертном заключении, действительно содержит определение понятия «ребенок» в п.1. ст. 54, принятое на основе положений Конвенции ООН 1989 г. «О правах ребенка» [8] (далее - Конвенция о правах ребенка): «Ребенком признается лицо, не достигшее возраста восемнадцати лет (совершеннолетия)». Как отмечается в научной литературе, российское определение лаконичнее международного, которое содержит дополнительную оговорку: «если по закону, применимому к данному ребенку, он не достигает совершеннолетия ранее» [9, с. 149]. Отсутствие такого уточнения, а также несовпадение в российском законодательстве категорий совершеннолетия и дееспособности порождает трудности в соотношении гражданской и семейной дееспособности ребенка. Так, гражданское законодательство будет считать эмансипированного несовершеннолетнего полностью самостоятельным, a c точки зрения семейного законодательства его статус будет характеризоваться рядом ограничений. Например, эмансипированный несовершеннолетний вынужден будет получать разрешение на вступление в брак, поскольку соответствующая возможность возникает в силу ст.13 СК РФ не с момента обретения полной гражданской дееспособности, а с момента достижения возраста 18 лет. Вместе с тем в п. 2 ст. 61 СК
РФ установлено, что родительские права прекращаются не только по достижении детьми совершеннолетия, но и при вступлении несовершеннолетних детей в брак и в других установленных законом случаях приобретения детьми полной гражданской дееспособности до достижения ими совершеннолетия. Для более точной содержательной интерпретации легального понятия «ребенок» данное положение необходимо учитывать во взаимосвязи с указанной выше формулировкой п.1 ст. 54 СК РФ. По утверждению ученых, такая конкретизация приводит к выводу о том, что законодатель подразумевает под анализируемым понятием более широкое по смыслу, чем закрепленное в п. 1 ст. 54 СК РФ. Иначе, как пишет О. И. Величкова, возможен ряд абсурдных утверждений. Например, признание несовершеннолетнего, вступившего в брак, нуждающимся в устройстве в семью органами опеки и попечительства на том основании, что в силу буквального толкования он является ребенком, родительская опека над которым утрачена [9, с. 150]. Таким образом, применяя понятие «ребенок» в семейном праве, мы будем подразумевать человека, не достигшего восемнадцати лет, не вступившего в брак и не приобретшего полной дееспособности по иным основаниям. Думается, что данная содержательная интерпретация должна получить отражение в ст. 54 СК РФ.

Чрезвычайно важным моментом является то, что легального определения понятия «родитель» не существует. На момент принятия действующего СК РФ было оправданно воспроизведено имевшееся в советском законодательстве утверждение о том, что «права и обязанности родителей и детей основываются на происхождении детей, удостоверенное в установленном законом порядке» (ст. 47 СК РФ). Однако в текущий период времени изменился сам субъект права - человек, и изменились его возможности. Факты широкого использования вспомогательных репродуктивных технологий (далее-ВРТ) и распространение института суррогатного материнства говорят о том, что происхождение уже не является единственным определяющим критерием родительства. Так, например, в случае приобретения родительского статуса на основании договора с суррогатной матерью при использовании донорского биологического материала между ребенком и родителем вообще отсутствует биологическая связь, которая давала бы повод говорить о происхождении. Таким образом, существует необходимость научного анализа и поиска актуальных сущностных характеристик понятия «родитель». Полагаем, что родителем является человек, взявший на себя нравственное обязательство 
заботиться о рождении и дальнейшем развитии ребенка. Вместе с тем в правовой плоскости корректнее говорить об ответственности, которую человек принимает на себя добровольно (путем регистрации в органах загс в качестве матери или отца) или в соответствии с решением суда. В этом случае имеются смысловые связи: и при буквальном прочтении - отвечать за (вместо) ребенка, что отражает функцию по восполнению родителями дееспособности своего ребенка, и в словарном значении слова «ответственность», как положение, при котором обязанное лицо принимает на себя вину за все возможные последствия [10]. К тому же термин «родительская ответственность» фигурирует на международном уровне. Не так давно Россия стала участницей Конвенции о гражданско-правовых аспектах международного похищения детей (Гаага, 25 октября 1980 года) [11] и Конвенции о юрисдикции, применимом праве, признании, исполнении и сотрудничестве в отношении родительской ответственности и мер по защите детей (далее - Конвенция о родительской ответственности) [12]. Указанный термин содержится в Конвенции о родительской ответственности, хотя имеет весьма широкое значение в целях этого документа.

Смыслообразующим критерием в искомом определении должна быть естественно-правовая природа отношений родителей и детей. Важными представляются выводы ученых относительно основных целей реализации родительских прав - автономия личности и социализация [13]. Таким образом, на основе уже имеющихся данных и научных исследований мы предлагаем следующее определение понятия «родитель»: это мужчина (отец) и (или) женщина (мать), принявшие на себя ответственность за обеспечение безопасности ребенка, его развитие и социализацию.

Теоретической и практической значимостью обладает исследование вопросов родительской правосубъектности. Так, например, требует юридического обоснования реализация представительских функций родителями в отношении новорожденного (дача согласия на медицинское вмешательство и т.д.) до регистрации его рождения и указания соответствующих лиц в качестве родителей. Такая ситуация имеет место практически во всех случаях рождения ребенка в медицинской организации и открывает перспективу правовых конфликтов post factum. Например, согласие отца на прививку новорожденному юридически безразлично. Ведь если рождение ребенка не было зарегистрировано, то юридическая связь между родителем и ребенком отсутствует, невозможно их представительство от имени ребенка, совершение любых юридически значимых действий.
Анализ законодательства (ст. 47 СК РФ, ст. 14 Федерального закона от 15.11.1997 № 143-Ф3 «Об актах гражданского состояния», далее - Закон об актах гражданского состояния) и научных позиций [14, с. 16] дает основание утверждать, что на сегодняшний день родительское правоотношение возникает с момента государственной регистрации рождения ребенка и регистрации соответствующих лиц в качестве его родителей. Как известно, между моментом рождения и моментом его регистрации может пройти существенный промежуток времени: согласно п.6 ст. 16 Закона об актах гражданского состояния, заявление о рождении ребенка должно быть сделано не позднее чем через месяц со дня рождения ребенка. Более того, ст. 21 Закона об актах гражданского состояния устанавливает порядок регистрации рождения ребенка, достигшего возраста 1 года и более (вплоть до достижения ребенком совершеннолетия). Следовательно, весь этот период времени нет юридической возможности утверждать наличие родительского правоотношения.

Отметим, что в научной литературе существует мнение, что было бы справедливо моментом возникновения родительских обязанностей считать возникновение факта беременности женщины, потому что закон уже наделяет некоторыми правами и возлагает некоторые обязанности на родителей ребенка. Так, по мнению А. К. Поляниной, «ребенок, находящийся в периоде эмбрионального развития, уже может быть наделен правом на заботу со стороны родителей, обеспечение его интересов и всестороннее развитие. Родители при этом несут ответственность за воспитание и развитие своих детей, в том числе и находящихся в утробе матери» [15, С.10]. Известный ученый К. П. Победоносцев писал в IX веке: «зачатие ребенка принадлежит к тайнам природы, есть действие, которое не может быть уловлено во времени со всей своей обстановкой» $[16$, с. 137]. Данное утверждение уже не соответствует реальности, особенно в случаях применения супругами методов вспомогательных репродуктивных технологий. Тем самым, нельзя исключать, что в будущем российское законодательство пойдет по пути развития, предложенном А. К. Поляниной. Однако в текущий период времени, полагаем, для защиты государством ребенка до его рождения существует множество препятствий. Так, например, отсутствие механизма удостоверения факта беременности с указанием матери и отца ребенка, индивидуальный подход в решении вопроса о факте и сроках постановки на учет в медицинской организации и вследствие этого потенциальное неравноправие детей. К ряду препятствующих фактов должны быть отнесены 
DOI: $10.7256 / 1811-9018.2015 .11 .16652$

При цитировании этой статьи сноска на доі обязательна

\section{Право и политика 11 (191) • 2015}

традиции цивилистической теории (вопросы правоспособности и др.) и законодательства (в частности, позиция законодателя по вопросу об абортах).

Отметим, что международное право не запрещает считать ребенком человеческое существо с момента зачатия. В соответствии с Конвенцией ООН о правах ребенка неотъемлемым правом несовершеннолетнего является право на выживание и здоровое развитие ребенка. Как отмечает А. М. Рабец, выживание и здоровое развитие ребенка должно обеспечиваться уже во внутриутробный период. По этой причине в международном праве остро встал вопрос об определении временного периода, с которого человеческое существо должно называться ребенком. Однако существующие между государствами различие в сфере культуры, правовых системах (в частности, различия в упомянутом выше законодательстве об абортах), делают невозможным дать точное определение понятия «ребенок», которое могло бы удовлетворить все заинтересованные стороны $[17$, C.222]. Тем самым на сегодняшний день по международному праву юридическим фактом необходимым и достаточным для возникновения прав ребенка является его рождение. Согласно ст. 7 Конвенции ООН О правах ребенка, ребенок регистрируется сразу же после рождения и с момента рождения имеет право на имя и на приобретение гражданства, а также, насколько это возможно, право знать своих родителей и право на их заботу. Таким образом, регистрация рождения ребенка должна рассматриваться как обязанность родителей, возникшая в связи с рождением ребенка, а порядок регистрации рождения ребенка, существующий в п.6 ст. 16 Закона об актах гражданского состояния, не соответствует требованиям международного законодательства.

Заметим, что задолго до появления Конвенции ООН о правах отечественными учеными обосновывалось, что ребенок является субъектом права в родительском правоотношении со времени рождения [18, с. 56].

Изложенное позволяет сделать вывод о необходимости обновления положений закона об основаниях и возникновения родительского правоотношения и приведении его в соответствие международному зако- нодательству. Заслуживает внимания опыт регистрации рождения в республике Татарстан, где ведется работа по организации пунктов регистрации рождения непосредственно в родильных домах [19].

Регистрация рождения ребенка фактически одновременно с его рождением позволит согласовать между собой доктринальные представления о правоспособности ребенка и их практическое воплощение. Позволит обеспечить правовую защиту ребенка в случаях, когда родители уклоняются от обращения в органы загса с заявлением о рождении ребенка (если речь не идет об установлении отцовства ребенка, рожденного вне брака). При этом важно, что на возникновение правового статуса родителя не влияет отсутствие направленного на это желания самого родителя, поскольку российское законодательство не содержит юридической возможности отказа от родительских прав. Между тем существует практика оформления родителями дачи согласия на усыновление на будущее время, что в целом формирует негативную тенденцию злоупотребления правом со стороны недобросовестных родителей. Ученые обращали внимание законодателя на то, что СК РФ допускает такую возможность, еще в советский исторический период [20, с.7], однако никаких преобразований к настоящему моменту не происходило. Для решения этой проблемы считаем необходимым скорректировать положение ст. 129 СК РФ, указав, что права и обязанности родителя, давшего согласие на усыновление (удочерение), сохраняются до фактического установления усыновления (удочерения) в отношении ребенка, за исключением случаев, когда ребенок в установленном законом порядке помещен на полное государственное попечение.

Подводя итог, подчеркнем, что вопрос об основаниях и моменте возникновения правового статуса родителя по изложенным выше основаниям должен быть отнесен к числу основополагающих в решении задач совершенствования семейного законодательства и получить отражение в содержании обсуждаемой Концепции совершенствования семейного законодательства Российской Федерации.

\section{Библиография:}

1. Третьяков С. К проблеме использования исторической аргументации в цивилистической догматике: в сб. История российских гражданских законов. Часть первая: Введение и книга первая о союзах семейственных. - м.: Статут, 2005. - 509 с. (Классика российской цивилистики).

2. Летова Н. В. Правовой статус ребенка в гражданском и семейном праве: автореф. дис. д-ра юрид наук. - М., 2013. $-46 \mathrm{c}$.

3. Мантулина О. О. Обязанности родителей по содержанию несовершеннолетних детей в России и зарубежных странах // Право и политика. - 2015. - № 9. - С. 1291 - 1297. DOI: 10.7256/1811-9018.2015.9.16171. 
4. Князева Е. В. Проблемы защиты прав несовершеннолетних // Семейное право на рубеже XX-XI веков: к 20-летию Конвенции ООН о правах ребенка: Материалы Международной научно-практической конференции, г. Казань, Казанский (Приволжский) федеральный университет, 18 декабря 2010 г. / Отв. ред. О. Н. Низамиева. - М.: Статут, 2011. - С. 164-167.

5. Указ Президента Российской Федерации от 01.06.2012 № 761 «О Национальной стратегии действий в интересах детей на 2012 - 2017 годы» // СПС КонсультантПлюс.

6. Концепция совершенствования семейного законодательства Российской Федерации и Предложений по совершенствованию семейного законодательства Совета при Президенте РФ по кодификации и совершенствованию гражданского законодательства от 07.07.2014 № 132-1/2014) [Электронный ресурс]. Документ опубликован не был. Доступ из справ. - правовой системы «КонсультантПлюс» (дата обращения 11. 10. 2015).

7. Экспертное заключение по проекту Концепции совершенствования семейного законодательства Российской Федерации и Предложений по совершенствованию семейного законодательства Совета при Президенте РФ по кодификации и совершенствованию гражданского законодательства от 07.07.2014 № 132-1/2014) [Электронный ресурс]. Документ опубликован не был. Доступ из справ. - правовой системы «КонсультантПлюс» (дата обращения 11. 10. 2015).

8. Конвенция ООН 1989 г. «О правах ребенка»// Ведомости Съезда народных депутатов СССР и Верховного Совета СССР от 7 ноября 1990 г. - № 45 . - Ст.955.

9. Величкова О. И. О понятии «ребенок» в свете положений Семейного кодекса РФ и Конвенции о правах ребенка//Семейное право на рубеже XX-XI веков: к 20-летию Конвенции ООН о правах ребенка: Материалы Международной научно-практической конференции, г. Казань, Казанский (Приволжский) федеральный университет, 18 декабря 2010 г. / Отв. ред. О. Н. Низамиева. - М.: Статут, 2011. - С. 149-152.

10. Ушаков Д. Н. Толковый словарь русского языка. - М.: Альта-Принт, 2005. - 1216 с.

11. Конвенции о гражданско-правовых аспектах международного похищения детей (Гаага, 25 октября 1980 года)// Бюллетень международных договоров. - 2013 г. - № 1.

12. Конвенция о юрисдикции, применимом праве, признании, исполнении и сотрудничестве в отношении родительской ответственности и мер по защите детей // Бюллетень международных договоров. - 2014 г. - № 1.

13. Темникова Н. А. Реализация и защита личных неимущественных прав ребенка в семейном праве России: дисс....канд. юрид. наук. - Омск, 2006. - 197 с.

14. Кумановская А. Л. Права и обязанности родителей по воспитанию детей в семейном праве Российской Федерации: дис... канд. юрид. наук. - М., 2005. - 169 с.

15. Полянина А. К. Факт беременности как основание возникновения родительских обязанностей // Семейное и жилищное право. - 2012. - №1. - С. 9-11.

16. Победоносцев К. П. Курс гражданского права. Часть вторая: Права семейственные, наследственные и завещательные. - М: Статут, 2003. - 639 с.

17. Рабец А. М. Право ребенка на выживание и здоровое развитие и его реализация в законодательстве Российской Федерации // Семейное право на рубеже XX-XI веков: к 20-летию Конвенции ООН о правах ребенка: Материалы Международной научно-практической конференции, г. Казань, Казанский (Приволжский) федеральный университет, 18 декабря 2010 г. / Отв. ред. О. Н. Низамиева. - М.: Статут, 2011. - С. 250-255.

18. Поссе Е.А., Фаддеева Т.А. Проблемы семейного права. - Л., 1976. - 115 с.

19. Зарипова Э.А. Роль органов ЗАГС в охране прав несовершеннолетних // Семейное право на рубеже XX-XI веков: к 20-летию Конвенции ООН о правах ребенка: Материалы Международной научно-практической конференции, г. Казань, Казанский (Приволжский) федеральный университет, 18 декабря 2010 г. / Отв. ред. О. Н. Низамиева. - М.: Статут, 2011. - С. 156-160.

20. Звягинцева Л. М., Кузнецова Л.Г. Задача совершенствования законодательства о браке и семье / Законодательство о браке и семье и практика его применения (к 20-летию Основ и КоБС РСФСР). - Свердловск, 1989. - С. 3-7.

\section{References (transliterated):}

1. Tret'yakov S. K probleme ispol'zovaniya istoricheskoi argumentatsii v tsivilisticheskoi dogmatike: v sb. Istoriya rossiiskikh grazhdanskikh zakonov. Chast' pervaya: Vvedenie i kniga pervaya o soyuzakh semeistvennykh. - m.: Statut, 2005 . - 509 s. (Klassika rossiiskoi tsivilistiki).

2. Letova N. V. Pravovoi status rebenka v grazhdanskom i semeinom prave: avtoref.dis....d-ra yurid nauk. - M., 2013. - 46 s.

3. Mantulina O. O. Obyazannosti roditelei po soderzhaniyu nesovershennoletnikh detei v Rossii i zarubezhnykh stranakh // Pravo i politika. - 2015. - № 9. - S. 1291 - 1297. DOI: 10.7256/1811-9018.2015.9.16171.

4. Knyazeva E. V. Problemy zashchity prav nesovershennoletnikh // Semeinoe pravo na rubezhe KhKh-KhI vekov: k 20-letiyu Konventsii OON o pravakh rebenka: Materialy Mezhdunarodnoi nauchno-prakticheskoi konferentsii, g. Kazan', Kazanskii (Privolzhskii) federal'nyi universitet, 18 dekabrya 2010 g. / Otv. red. O. N. Nizamieva. - M.: Statut, 2011. - S. 164-167.

5. Velichkova O. I. O ponyatii «rebenok» v svete polozhenii Semeinogo kodeksa RF i Konventsii o pravakh rebenka//Semeinoe pravo na rubezhe KhKh-KhI vekov: k 20-letiyu Konventsii OON o pravakh rebenka: Materialy Mezhdunarodnoi nauchno-prakticheskoi konferentsii, g. Kazan', Kazanskii (Privolzhskii) federal'nyi universitet, 18 dekabrya 2010 g. / Otv. red. O. N. Nizamieva. - M.: Statut, 2011. - S. 149-152.

6. Ushakov D. N. Tolkovyi slovar' russkogo yazyka. - M.: Al’ta-Print, 2005. - $1216 \mathrm{s.}$ 
DOI: 10.7256/1811-9018.2015.11.16652

При цитировании этой статьи сноска на dоі обязательна

\section{Право и политика $11(191) \cdot 2015$}

7. Temnikova N. A. Realizatsiya i zashchita lichnykh neimushchestvennykh prav rebenka v semeinom prave Rossii: disc....kand. yurid. nauk. - Omsk, 2006. - 197 s.

8. Kumanovskaya A. L. Prava i obyazannosti roditelei po vospitaniyu detei v semeinom prave Rossiiskoi Federatsii: dis...kand. yurid. nauk. - M., 2005. - 169 s.

9. Polyanina A. K. Fakt beremennosti kak osnovanie vozniknoveniya roditel'skikh obyazannostei // Semeinoe i zhilishchnoe pravo. - 2012. - №1. - S. 9-11.

10. Pobedonostsev K. P. Kurs grazhdanskogo prava. Chast' vtoraya: Prava semeistvennye, nasledstvennye i zaveshchatel'nye. - M: Statut, 2003. - 639 s.

11. Rabets A. M. Pravo rebenka na vyzhivanie i zdorovoe razvitie i ego realizatsiya v zakonodatel'stve Rossiiskoi Federatsii // Semeinoe pravo na rubezhe KhKh-KhI vekov: k 20-letiyu Konventsii OON o pravakh rebenka: Materialy Mezhdunarodnoi nauchno-prakticheskoi konferentsii, g. Kazan', Kazanskii (Privolzhskii) federal'nyi universitet, 18 dekabrya 2010 g. / Otv. red. O. N. Nizamieva. - M.: Statut, 2011. - S. 250-255.

12. Posse E.A., Faddeeva T.A. Problemy semeinogo prava. - L., 1976. - 115 s.

13. Zaripova E.A. Rol' organov ZAGS v okhrane prav nesovershennoletnikh // Semeinoe pravo na rubezhe KhKh-KhI vekov: k 20-letiyu Konventsii OON o pravakh rebenka: Materialy Mezhdunarodnoi nauchno-prakticheskoi konferentsii, g. Kazan', Kazanskii (Privolzhskii) federal'nyi universitet, 18 dekabrya 2010 g. / Otv. red. O. N. Nizamieva. - M.: Statut, 2011. - S. 156-160.

14. Zvyagintseva L. M., Kuznetsova L.G. Zadacha sovershenstvovaniya zakonodatel'stva o brake i sem'e / Zakonodatel'stvo o brake i sem'e i praktika ego primeneniya (k 20-letiyu Osnov i KoBS RSFSR). - Sverdlovsk, 1989. - S. 3-7. 